\title{
Association of Oxidative Stress Markers with Vascular Stiffness Parameters in Patients with Diabetic Neuropathy
}

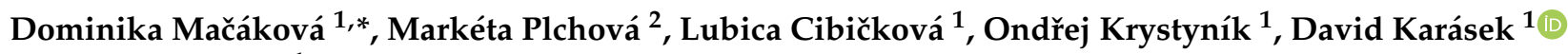 \\ and Josef Zadrazil ${ }^{1}$
}

Citation: Mačáková, D.; Plchová, M.; Cibičková, L.; Krystyník, O.; Karásek, D.; Zadrazil, J. Association of Oxidative Stress Markers with Vascular Stiffness Parameters in Patients with Diabetic Neuropathy. BioMed 2022, 2, 1-12. https://doi.org/10.3390/ biomed2010001

Academic Editor: Wolfgang Graier

Received: 9 November 2021

Accepted: 28 December 2021

Published: 30 December 2021

Publisher's Note: MDPI stays neutral with regard to jurisdictional claims in published maps and institutional affiliations.

Copyright: (C) 2021 by the authors. Licensee MDPI, Basel, Switzerland. This article is an open access article distributed under the terms and conditions of the Creative Commons Attribution (CC BY) license (https:// creativecommons.org/licenses/by/ $4.0 /)$.
1 Department of Internal Medicine-Nephrology, Rheumatology and Endocrinology, University Hospital Olomouc and Faculty of Medicine, Palacký University in Olomouc, 77900 Olomouc, Czech Republic; lubica.cibickova@fnol.cz (L.C.); ondrej.krystynik@fnol.cz (O.K.); david.karasek@fnol.cz (D.K.); josef.zadrazil@fnol.cz (J.Z.)

2 Department of Clinical Biochemistry, University Hospital Olomouc, 77900 Olomouc, Czech Republic; marketa.plchova@fnol.cz

* Correspondence: goldmannovadominika@seznam.cz; Tel.: +420-602-437-884

\begin{abstract}
Introduction: One of the most common chronic complications of diabetes mellitus is diabetic neuropathy. The aim of the study was to elucidate the association between selected markers of oxidative stress and markers of vascular stiffness and to contribute to the understanding of the pathophysiological links between oxidative stress and micro- and macrovascular complications of diabetes. Methods: We enrolled patients with type $2 \mathrm{DM}(n=49)$, with moderate to severe diabetic polyneuropathy of lower extremities, and a control group without microvascular complications $(n=29)$. The neuropathy group received alpha-lipoic acid infusion therapy. Sampling was performed before and after treatment to determine the level of oxidative markers (advanced glycation end-products-AGEs, glycation products of AOPP proteins, MDA malondialdehyde and oxidized LDL), parameters of metabolic control and parameters of vascular wall stiffness were measured by sphygmomanometry. Results: After the administration of alpha-lipoic acid, we demonstrated a significant reduction in the level of three selected oxidation markers (AOPP: $p<0.001$, AGE: $p<0.001$, oxLDL: $p<0.05)$. In contrast, the level of MDA did not change significantly $(p=0.83)$. Throughout the group, oxLDL was significantly correlated with central BP (SBP and DBP in the aorta, $p<0.05$ and $<0.01$ ) and with the augmentation index (AiX/75 bpm, $p<0.01)$. AOPP significantly correlated with systolic BP in the aorta $(p<0.05)$. We did not find significant associations in the remaining oxidation markers. Conclusion: In our study, we demonstrated a reduction in the level of oxidative markers after alpha-lipoic acid administration and also an association between markers of oxidative damage to lipids and proteins (oxLDL and AOPP) and some parameters of vascular stiffness.
\end{abstract}

Keywords: oxidative stress; alpha-lipoic acid; vascular stiffness

\section{Introduction}

Diabetic neuropathy is one of the chronic microvascular complications of diabetes and is defined as a non-inflammatory impairment of the function and structure of peripheral somatic or autonomic nerves due to metabolic-vascular pathology [1]. In the early stages of diabetes, hyperglycaemia causes changes in blood flow and vascular permeability [2]. The damage of vasa nervorum is first manifested by functional changes, where vasoconstrictive factors predominate over vasodilators and coagulation is activated. Over time, disruption of glucose metabolism reduces intracellular NADPH levels and reduces the synthesis of myo-inositol, which is required for normal neuronal function [3]. Impaired glucose metabolism in diabetic patients induces oxidative stress as a result of the transfer of excess glucose, which is not adequately oxidized in mitochondria, to other metabolic or nonmetabolic biochemical processes [2]. This leads to the accumulation of toxic metabolites, 
excessive consumption of NADPH and abnormal modification of proteins, lipids and DNA [4-6], contributing to mitochondrial damage and ROS overproduction.

The measurement of oxidative stress markers is a necessary step for a better understanding of the pathogenesis and for the development of treatment in patients with DM neuropathy. It is possible to measure the total antioxidant capacity, enzymatic and non-enzymatic antioxidants, ROS production and damage products of biomolecules by oxidative stress. Markers of lipid damage include lipoperoxidation products such as malondialdehyde (MDA), 4-hydroxynonenal and F2-isoprostanes, and other molecules such as oxidized low density lipoproteins (OxLDL). Advanced protein oxidation (AOPP) or 3-nitrotyrosine products are used as protein markers and 8-hydroxy-2-deoxyguanosine as DNA damage markers [7]. Alpha-lipoic acid (ALA, thioctic acid) is an option for the treatment of diabetic neuropathy mainly due to its ability to induce relief from annoying symptoms, which has been confirmed in several studies [8-10]. ALA reduces oxidative stress by inhibiting the hexosamine pathway of glucose utilization and reduces AGE production. It further improves blood flow by increasing endothelial vasodilation via nitric oxide [11] and contributes to improved signal conduction in the peripheral nervous system.

Blood vessels age naturally during life. Aging leads to increased vascular stiffness and thus to an increase in pulse wave velocity (PWV) - this wave returns to the heart in the systole phase, where it contributes to increased blood pressure, left ventricular afterload and decreased coronary flow. The gold standard for measuring vascular aging is vascular stiffness analysis, where the above PWV is the most recognized parameter. Central blood pressure (systolic, diastolic, pulse-SBK, DBK, $\mathrm{PBK}$, etc.) or augmentation index (AI), which quantifies the increase in pulse pressure caused by the arrival of the reflected pulse wave, is also a useful marker of arterial stiffness. Pulse wave analysis is considered a biomarker of vascular damage and possible future cardiovascular events in the diabetic population [12] Oxidative stress can be associated with arterial stiffness, especially in the elderly $[13,14]$. The aim of this study was to determine whether the administration of alpha-lipoic acid can reduce the markers of oxidative stress that are involved in the pathogenesis of diabetes. We also examined whether these markers correlated with vascular stiffness parameters as a marker of cardiovascular risk in patients.

\section{Materials and Methods}

\subsection{Study Design}

This case-control study involving patients with type 2 diabetes mellitus with and without microvascular complications was performed in accordance with the principles of the Declaration of Helsinki for experiments involving humans. All participants initially signed an informed consent to the scheduled examinations. A thorough history of patients was recorded, with a focus on the treatment and duration of diabetes, its complications, medication and possible cardiovascular disease. The enrolled patients were diabetic patients in long-term management-in 16\% of cases with oral hypoglycemic agents (OHA), $53 \%$ of patients with insulin therapy $+\mathrm{OHA}$ and $15 \%$ with insulin monotherapy. As for macrovascular complications, $85 \%$ of patients had arterial hypertension, ischemic heart disease in $5 \%$, ischemic lower limb disease in $2 \%$ and stroke in $1 \%$ of cases.

Exclusion criteria were another type of diabetes mellitus (type 1, secondary or genetic), acute infection, cancer or trauma (Figure 1).

Our study included 49 patients with EMG-verified diabetic polyneuropathy of lower limbs (13 females, 36 males, age $=62.5 \pm 9.8$ ). These patients received a series of alphalipoic acid infusion treatments (10 infusions of $600 \mathrm{mg}$ of active substance, each infusion containing $600 \mathrm{mg}$ of alpha-lipoic acid in $50 \mathrm{~mL}$ solution administered intravenously) over 5 days. Prior to therapy, patients underwent laboratory tests-oxidation markers (advanced protein oxidation products (AOPP), advanced glycation end-products (AGEs), malondialdehyde (MDA) and oxidized low density lipoproteins (OxLDL), basic clinical biochemistry with a focus on lipids (cholesterol, TAG, HDL, LDL, ApoA, ApoB) and a marker of endothelial dysfunction (type 1 plasminogen activator inhibitor PAI-1). Sampling 
for oxidative stress markers was repeated at the end of hospitalization after the end of alpha-lipoic acid therapy.

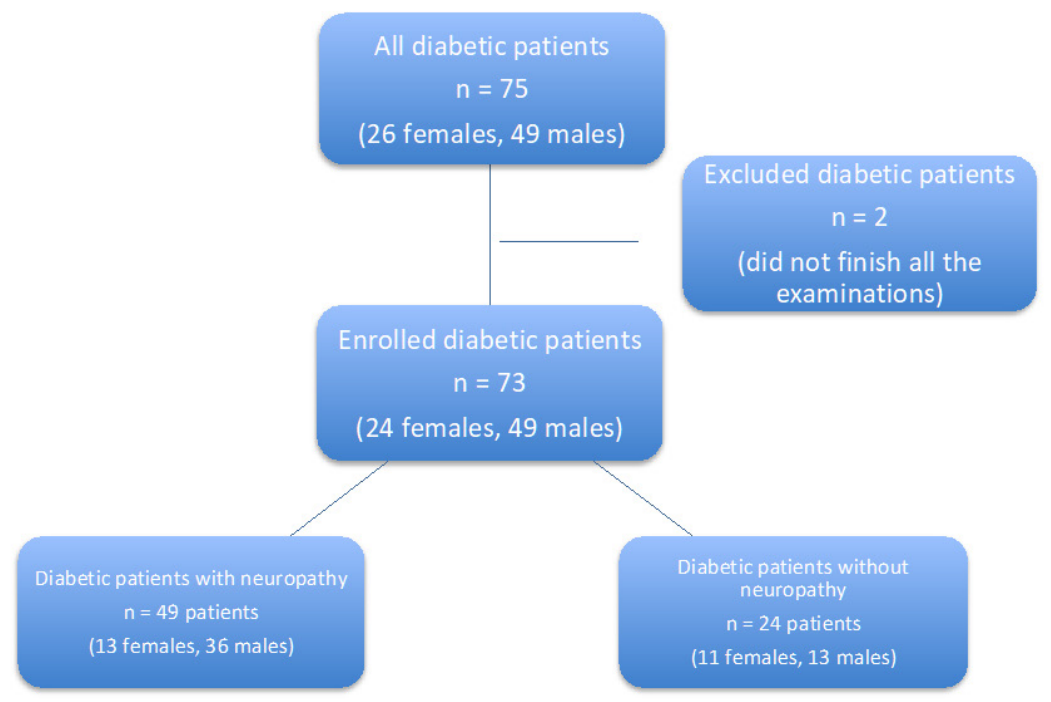

Figure 1. Flow chart diagram.

The control group included 24 patients with type 2 diabetes mellitus without confirmed micro or macrovascular complications (11 females, 13 males, age $=51.6 \pm 14.1$ ) who underwent the same clinical and laboratory examinations. $45 \%$ of patients were treated with OHA, 33\% with insulin + OHA combination and in 20\% with insulin monotherapy. Measurement of vascular stiffness parameters was always performed in the morning and in the group of patients before the start of alpha-lipoic acid administration.

\subsection{Laboratory Methods}

Whole blood samples were centrifuged after the collection to determine oxidation markers and blood sera were stored at $-70{ }^{\circ} \mathrm{C}$ prior to the analysis.

Serum AOPPs were measured spectrophotometrically according to the Witko-Sarsat method [15]. Helios Beta spectrophotometer (Thermo Spectronic, Leicester, UK) was used.

Serum AGEs were determined fluorimetrically with the modified protocol of Villa et al. [16] (Victor X fluorimeter, Perkin Elmer, Boston, MA, USA). Results are stated in arbitrary units per gram of protein.

Serum OxLDL concentrations were measured using the Mercodia Oxidized LDL ELISA kit (Mercodia, Uppsala, Sweden). The method is based on direct sandwich techniques and uses two monoclonal antibodies against different antigenic determinants of the oxidized apolipoprotein B molecule.

Serum MDA concentrations were measured using the ELISA Kit for Malondialdehyde (Cloud-Clone Corp., Houston, TX, USA). The method is based on a competitive inhibition technique and uses monoclonal antibody competition between biotinylated MDA and MDA in the sample. Biochemical parameters were measured using the Cobas 8000 analyzer (Roche Diagnostics, Penzberg, Germany).

Samples for metabolic parameters were collected every morning after a minimum of $8 \mathrm{~h}$ of fasting. Total cholesterol, TAG and HDL were determined enzymatically on a modular SWA (Serum work area) system (Roche, Basel, Switzerland). HDL determination was performed via a direct method without precipitation of lipoproteins containing apolipoprotein B. LDL was calculated using Freiwald's formula (LDL $=$ cholesterol-TAG $\times 0.4537-\mathrm{HDL}$, for TAG $<4.5 \mathrm{mmol} / \mathrm{L}$ ). Non-HDL was also calculated (nonHDL = cholesterol-HDL). 


\subsection{Measurement of Vascular Stiffness}

Patients underwent further non-invasive measurement of parameters of vascular wall stiffness. The measured parameters included aortic systolic, diastolic and pulse pressure (Ao SBP, DBP, PBK), augmentation pressure (AP), augmentation index corrected for heart rate 75 beats $/ \mathrm{min}(\mathrm{AiX} / 75 \mathrm{bpm}$ ) and pulse wave velocity (PWV). These parameters were measured using the SfygmoCor instrument (AtCor Medical Pty Ltd. Head Office, West Ryde, NSW, Australia). The examination was performed after instructing patients not to use caffeine and alcohol or smoke $12 \mathrm{~h}$ before the test. Patients were examined in a temperature-controlled room after a minimum of $15 \mathrm{~min}$ of rest. The first part of the pulse wave analysis took place while sitting, when peripheral parameters (radial artery) were measured; the device then performed a mathematical conversion to the aortic pulse wave. PWV was measured in the supine position, where we measured the pulse wave at the carotid and femoral arteries together with the ECG. The software then processed data from each pulse wave and acquired ECG to calculate the time difference between the heart and peripheral arteries, averaging 10 consecutive cycles. We used a measuring tape to measure the distance and utilised the point of instrument sensor application (on the carotid and femoral arteries) and the jugular fossa. PWV was then calculated according to the formula: $\operatorname{PWV}(\mathrm{m} / \mathrm{s})=$ carotid-femoral distance $(\mathrm{m}) /$ carotid-femoral transmission time $(\mathrm{s})[17,18]$.

\subsection{Statistical Analysis}

All statistical values are given either as means with standard deviation or medians with a distribution between the 1st and 3rd quartiles in non-normal distributions. Differences between groups were assessed using the Wilcoxon test and adjusted for age and sex. Pearson correlations were performed in the whole cohort to determine the associations between the measured parameters. Multivariate regression analysis was performed to determine independent associations between variables.

Alpha of 0.05 was considered statistically significant.

\section{Results}

In the first part of the statistical evaluation, we focused on comparing the group of patients and controls, after adjusting for age and sex. The basic characteristics of the cohort are given in Tables 1 and 2. The two groups did not differ significantly in the parameters of diabetes control, but the control group showed marginally higher BMI values and worse lipidogram parameters, especially LDL cholesterol. In terms of the evaluation of vascular stiffness, we found a significant difference and worse parameters for a group of patients in aortic pulse pressure and pulse wave velocity PWV. In addition, the patient group has a statistically significantly worse marker of endothelial dysfunction PAI-1.

The levels of oxidative markers in the group of patients and controls differed significantly only in the AGE parameter. However, after the administration of alpha-lipoic acid, there was a significant decrease in the levels of three measured oxidation markers (AOPP, AGE, oxLDL); the level of MDA did not decrease significantly, see Table 3.

In the second part of the statistical evaluation, we clarified whether the markers of oxidative stress are related to metabolic control of diabetic patients and then possibly to the parameters evaluating vascular stiffness.

OxLDL (ApoB, cholesterol, nonHDL, TAG, Chol/HDL, HDL, LDL, HbA 1 , PAI-1, BMI) showed the highest number of significant correlations. Similarly, AOPP (ApoB, cholesterol, nonHDL, TAG, Chol/HDL, HDL, $\mathrm{HbA}_{1 \mathrm{c}}$, PAI-1, BMI). AGEs are statistically significantly correlated with a smaller number of parameters of metabolic control (borderline nonHDL, TAG, LDL, CRP) and MDA correlated only with ApoA, see Table 4. 
Table 1. Basic characteristics of the cohort.

\begin{tabular}{cccc}
\hline & Patients $(\boldsymbol{n}=\mathbf{4 9})$ & Controls $(\boldsymbol{n}=\mathbf{2 4})$ & $p$ \\
\hline $\mathrm{BMI}\left(\mathrm{kg} / \mathrm{m}^{2}\right)$ & $30.6(27.9-34.8)$ & $34.3(31.3-39.5)$ & $<0.05$ \\
\hline $\mathrm{HbA}_{1 \mathrm{c}}(\mathrm{mmol} / \mathrm{mol})$ & $66(48-77)$ & $51(43-75.2)$ & n.s. \\
\hline Cholesterol $(\mathrm{mmol} / \mathrm{L})$ & $4.06 \pm 0.86$ & $4.35 \pm 0.97$ & n.s. \\
\hline $\mathrm{TAG}(\mathrm{mmol} / \mathrm{L})$ & $2.05(1.61-3.63)$ & $1.55(1.19-2.4)$ & n.s. \\
\hline $\mathrm{HDL}(\mathrm{mmol} / \mathrm{L})$ & $1.12 \pm 0.29$ & $1.18 \pm 0.33$ & n.s. \\
\hline $\mathrm{LDL}(\mathrm{mmol} / \mathrm{L})$ & $1.78 \pm 0.63$ & $2.33 \pm 0.87$ & $<0.01$ \\
\hline $\mathrm{Chol} / \mathrm{HDL}$ & $3.85 \pm 1.34$ & $3.93 \pm 1.27$ & n.s. \\
\hline $\mathrm{nonHDL}$ & $2.94 \pm 0.87$ & $3.2 \pm 1.01$ & n.s. \\
\hline ApoA $(\mathrm{g} / \mathrm{L})$ & $1.44(1.23-1.55)$ & $1.46(1.39-1.67)$ & n.s. \\
\hline ApoB $(\mathrm{g} / \mathrm{L})$ & $0.9(0.77-1.02)$ & $0.94(0.81-1.1)$ & n.s.
\end{tabular}

$\overline{\mathrm{BMI}}=$ body mass index $; \mathrm{HbA}_{1 \mathrm{c}}=$ glycated haemoglobin; $\mathrm{TAG}=$ triacylglycerols; $\mathrm{HDL}=$ high density lipoprotein, $\mathrm{LDL}=$ low density lipoprotein; $\mathrm{Chol} / \mathrm{HDL}=$ cholesterol and $\mathrm{HDL}$ ratio; $\mathrm{ApoA}=$ apolipoprotein $\mathrm{A}$ $\mathrm{ApoB}=$ apolipoprotein B; n.s. = non-significant. Data are presented as means in case of normal distribution (with standard deviation) or medians in case of non-normal distribution; $p<0.05$ is considered statistically significant.

Table 2. Vascular wall stiffness parameters and markers of endothelial dysfunction.

\begin{tabular}{cccc}
\hline & Patients & Controls & $p$ \\
\hline Ao SBP $(\mathrm{mmHg})$ & $119.7 \pm 13.1$ & $117.2 \pm 12.2$ & n.s. \\
\hline Ao DBP $(\mathrm{mmHg})$ & $79.3 \pm 9.9$ & $81.9 \pm 11.8$ & n.s. \\
\hline Ao PBP $(\mathrm{mmHg})$ & $39.4 \pm 10.7$ & $33.5 \pm 7.9$ & $<0.05$ \\
\hline AP $(\mathrm{mmHg})$ & $9.9 \pm 5.9$ & $8.2 \pm 4.2$ & n.s. \\
\hline AiX $(\% / 75 \mathrm{bpm})$ & $21.7 \pm 12.7$ & $20.1 \pm 8.2$ & n.s. \\
\hline PWV $(\mathrm{m} / \mathrm{s})$ & $11.6 \pm 4.6$ & $8.8 \pm 1.9$ & $<0.001$ \\
\hline PAI-1 $(\mathrm{ng} / \mathrm{mL})$ & $45.8(19.6-85.1)$ & $21(13.5-36.4)$ & $<0.05$
\end{tabular}

Ao SBP = aortic systolic pressure; Ao DBP = aortic diastolic pressure; Ao PBP = aortic pulse pressure; AP = augmentation pressure; $\mathrm{AiX}=$ augmentation index; n.s. = non-significant; $\mathrm{PWV}=$ pulse wave velocity; PAI-1 = plasminogen activator inhibitor 1. Data are presented as means in case of normal distribution (with standard deviation) or medians in case of non-normal distribution; $p<0.05$ is considered statistically significant.

Table 3. Markers of oxidative stress before and after treatment + control.

\begin{tabular}{cccccc}
\hline $\begin{array}{c}\text { Oxidation } \\
\text { Markers }\end{array}$ & $\begin{array}{c}\text { Patients } \\
\text { before }\end{array}$ & $\begin{array}{c}\text { Patients } \\
\text { after }\end{array}$ & $\begin{array}{c}\boldsymbol{p} \text { (Patients before } \\
\text { and after Therapy) }\end{array}$ & Controls & $\begin{array}{c}\boldsymbol{p} \text { (Patients before } \\
\text { vs. Controls }\end{array}$ \\
\hline $\mathrm{AOPP}(\mu \mathrm{mol} / \mathrm{L})$ & 211.2 & 142.5 & $2.54 \times 10^{-6}$ & 193.8 & 0.39 \\
\hline $\mathrm{AGE}(\mathrm{AU} / \mathrm{g})$ & $13,331.55$ & $10,984.38$ & $1.32 \times 10^{-7}$ & $10,334.89$ & 0.0031 \\
\hline $\mathrm{MDA}(\mu \mathrm{mol} / \mathrm{L})$ & 68.37 & 71.52 & 0.83 & 62.23 & 0.34 \\
\hline OxLDL $(\mathrm{U} / \mathrm{L})$ & 40.42 & 38.25 & 0.03 & 45.63 & 0.94 \\
\hline
\end{tabular}

AOPP = advanced oxidation protein products; AGE = advanced glycation end-products; MDA = malondialdehyde OxLDL $=$ oxidized low density lipoprotein. $p<0.05$ is considered statistically significant.

Since we assume a relationship between the degree of oxidative stress and vascular wall damage, we performed a statistical analysis to evaluate eventual correlations between oxidative stress markers and pulse wave parameters (for the whole cohort). There was a significant and most common relationship between the marker of oxidative lipid damage (oxLDL) and vascular stiffness parameters (SBP ao, DBP ao, AiX/75 bpm). AOPP also correlated significantly with systolic blood pressure in the aorta (SBP ao), see Table 5 for values. The remaining oxidation markers (MDA and AGE) in our study showed no significant correlations with vascular stiffness parameters. 
Table 4. Correlation of oxidative markers and metabolic parameters.

\begin{tabular}{|c|c|c|c|c|}
\hline & oxLDL & AOPP & AGE & MDA \\
\hline cholestrol & $\begin{aligned} \mathrm{r} & =0.76 \\
p & <0.001\end{aligned}$ & $\begin{aligned} \mathrm{r} & =0.24 \\
p & <0.001\end{aligned}$ & n.s. & n.s. \\
\hline TAG & $\begin{array}{c}r=0.5 \\
p<0.001\end{array}$ & $\begin{array}{c}r=0.82 \\
p<0.001\end{array}$ & $\begin{array}{c}r=0.35 \\
p=0.049\end{array}$ & n.s. \\
\hline HDL & $\begin{array}{l}r=-0.18 \\
p=0.009\end{array}$ & $\begin{array}{l}\mathrm{r}=-0.3 \\
p=0.005\end{array}$ & n.s. & n.s. \\
\hline LDL & $\begin{array}{c}r=0.46 \\
p<0.001\end{array}$ & n.s. & $\begin{array}{c}r=0.22 \\
p=0.034\end{array}$ & n.s. \\
\hline nonHDL & $\begin{array}{c}r=0.84 \\
p<0.001\end{array}$ & $\begin{array}{c}r=0.34 \\
p<0.001\end{array}$ & $\begin{array}{l}r=0.06 \\
p=0.05\end{array}$ & n.s. \\
\hline Chol/HDL & $\begin{array}{c}\mathrm{r}=0.71 \\
p<0.001\end{array}$ & $\begin{array}{c}r=0.55 \\
p<0.001\end{array}$ & n.s. & n.s. \\
\hline ApoB & $\begin{array}{c}r=0.77 \\
p=0.008\end{array}$ & $\begin{array}{c}r=0.1 \\
p=0.033\end{array}$ & n.s. & n.s. \\
\hline ApoA & n.s. & n.s. & n.s. & $\begin{array}{l}r=-0.11 \\
p=0.001\end{array}$ \\
\hline $\mathrm{HbA}_{1 \mathrm{c}}$ & $\begin{array}{c}r=0.32 \\
p=0.039\end{array}$ & $\begin{array}{c}r=0.31 \\
p=0.048\end{array}$ & n.s. & n.s. \\
\hline PAI-1 & $\begin{array}{c}r=0.43 \\
p=0.003\end{array}$ & $\begin{array}{c}r=0.55 \\
p<0.001\end{array}$ & n.s. & n.s. \\
\hline BMI & $\begin{array}{c}r=0.29 \\
p=0.036\end{array}$ & $\begin{array}{c}r=0.44 \\
p=0.013\end{array}$ & n.s. & n.s. \\
\hline CRP & n.s. & n.s. & $\begin{array}{l}r=0.036 \\
p<0.001\end{array}$ & n.s. \\
\hline
\end{tabular}

AOPP = advanced oxidation protein products; AGE = advanced glycation end-products; MDA = malondialdehyde; OxLDL = oxidized low density lipoprotein; TAG = triacylglycerols; HDL $=$ high density lipoprotein $\mathrm{LDL}=$ low density lipoprotein; nonHDL = cholesterol contained in potentially atherogenic lipoprotein particles (LDL, IDL, VLDL, residual chylomicrons; Chol/HDL = cholesterol and HDL ratio); ApoA = apolipoprotein A $\mathrm{ApoB}=$ apolipoprotein $\mathrm{B} ; \mathrm{HbA}_{1 \mathrm{c}}=$ glycated haemoglobin; $\mathrm{PAI}-1=$ plasminogen activator inhibitor $1, \mathrm{BMI}=$ body mass index, $\mathrm{CRP}=\mathrm{C}$-reactive protein; n.s. $=$ non-significant. $\mathrm{r}=$ Pearson correlation coefficient; $p<0.05$ was considered statistically significant.

Table 5. Correlation of oxidative stress markers and pulse wave parameters.

\begin{tabular}{ccccc}
\hline & oxLDL & AOPP & AGE & MDA \\
\hline SBP ao & $\begin{array}{c}\mathrm{r}=0.2 \\
p<0.05\end{array}$ & $\begin{array}{c}\mathrm{r}=0.098 \\
p<0.05\end{array}$ & n.s. & n.s. \\
\hline DBP ao & $\begin{array}{c}\mathrm{r}=0.45 \\
p<0.01\end{array}$ & n.s. & n.s. & n.s. \\
\hline AP & n.s. & n.s. & n.s. & n.s. \\
\hline AiX/75 bpm & $\begin{array}{c}\mathrm{r}=0.46 \\
p<0.01\end{array}$ & n.s. & n.s. & n.s. \\
\hline PVW & n.s. & n.s. & n.s. & n.s. \\
\hline
\end{tabular}

$\overline{\mathrm{AOPP}}=$ advanced oxidation protein products; $\mathrm{AGE}=$ advanced glycation end-products; $\mathrm{MDA}=$ malondialdehyde OxLDL = oxidized low density lipoprotein; Ao SBP = aortic systolic pressure; Ao DBP $=$ aortic diastolic pressure; $\mathrm{AP}=$ augmentation pressure; $\mathrm{AiX}=$ augmentation index; $\mathrm{PWV}=$ pulse wave velocity; $\mathrm{n} . \mathrm{s} .=$ non-significant. $\mathrm{r}=$ Pearson correlation coefficient; $p<0.05$ was considered statistically significant.

To confirm the independent association between the measured variables, a multivariate regression analysis was performed-see Table 6. OxLDL was independently associated with parameters of metabolic compensation (nonHDL, ApoB, $\mathrm{HbA}_{1 \mathrm{c}}$ ) and with diastolic pressure in aorta and augmentation index (AiX/75 bpm). AOPP was independently associated with triacyglycerol levels and aortic systolic pressure. 
Table 6. Multivariate regression analysis of oxidation marker correlations.

\begin{tabular}{cccccccc}
\hline & TAG & nonHDL & ApoB & HbA $_{1 c}$ & SBP ao & DBP ao & AiX/75 bpm \\
\hline oxLDL & & $2.712^{* *}$ & $-2.343^{*}$ & $3.071^{* *}$ & & $2.729^{* *}$ & $2.776^{* *}$ \\
\hline AOPP & $7.094^{* * *}$ & & & & $2.293^{*}$ \\
\hline
\end{tabular}

AOPP = advanced oxidation protein products; OxLDL = oxidized low density lipoprotein; TAG = triacylglycerols nonHDL $=$ cholesterol contained in potentially atherogenic lipoprotein particles (LDL, IDL, VLDL, residual chylomicrons); $\mathrm{HbA}_{1 \mathrm{c}}=$ glycated haemoglobin; Ao SBP = aortic systolic pressure; Ao DBP = aortic diastolic pressure; $\mathrm{AiX}=$ augmentation index. Statistically significant values: ${ }^{*} p<0.05,{ }^{* *} p<0.01,{ }^{* *} p<0.001$.

\section{Discussion}

The presented study included a group of patients with diabetic neuropathy and a group of control patients-diabetic patients without microvascular complications. Both groups differed significantly in vascular stiffness (PBP et al., PWV), in the endothelial dysfunction marker PAI-1 and in the level of the oxidative marker AGE; other measured markers (AOPP, MDA, oxLDL) did not differ significantly between the groups. The level of oxidative markers (AOPP, AGE, oxLDL) decreased significantly after administration of alpha-lipoic acid; the level of MDA has not changed.

Higher AGE levels in patients with diabetic neuropathy compared to non-complicated diabetic patients are consistent with the fact that AGEs are associated with the progression of diabetic complications such as diabetic neuropathy, retinopathy, cardiomyopathy or peripheral arterial disease [19]. The level of oxidative markers correlated with the parameters of metabolic control in diabetic patients (oxLDL with cholesterol, TAG, HDL, LDL, nonHDL, chol/HDL, ApoB, HbA1c, PAI-1, BMI; AOPP with cholesterol, TAG, HDL, nonHDL, Chol/HDL, ApoB, HbA1c, PAI-1, BMI; AGE with TAG, LDL, nonHDL, CRP; MDA with ApoA). Oxidative stress plays a key role in the development of diabetes complications, both microvascular and cardiovascular. Experimental data suggest that metabolic abnormalities in diabetes cause overproduction of mitochondrial superoxide [20,21]. A number of studies indicate that obesity, insulin resistance, hypertension, dyslipidemia and diabetes cause mitochondrial oxidative stress, altered mitochondrial morphology and oxidative phosphorylation functions, as well as activation of mechanisms leading to induction of mitophagy and apoptosis [22]. In particular, the accumulation of free cholesterol, ox-LDL and glycated HDL has been reported to mediate endothelial dysfunction through ROS-mediated impairment of mitochondrial functions and adipocytokine release, which promotes atherogenic processes [23]. Several pro-inflammatory mediators known to promote oxidative stress are released in the vasculature, where they enhance endothelial dysfunction. Among these mediators, inflammatory cytokines, high glucose levels, and free fatty acids have been found to play a crucial role in deregulating the activity of ROS-producing systems such as NADPH oxidases, NOS, and mitochondrial oxidases [22,23]. We used PAI-1 to assess endothelial dysfunction. PAI-1 is a major physiological inhibitor of the fibrinolytic system and is produced by both endothelial cells and adipose tissue [24]. It is also reported to be associated with major cardiovascular events (MACE) [25]. PAI-1 levels have been shown to be elevated in patients with type $2 \mathrm{DM}[26,27]$. In our study, the group of patients had significantly higher PAI-1, although the control group was significantly more obese. PAI-1 was also associated with the level of oxidative markers (oxLDL and AOPP). In terms of pathophysiology, PAI-1 is upregulated by both protein kinase $C$ activation and the hexosamine pathway [28], the mechanisms of oxidative stress.

It is known that patients with type 2 DM have higher vascular stiffness than healthy individuals and that this correlates with the incidence of micro- and macrovascular complications of diabetes [29], which we confirmed in our study. We also demonstrated a correlation of oxidative markers with vascular stiffness parameters (oxLDL with SBPao, DBPao, AiX/75 min; AOPP with SBPao). The independent association of oxLDL with TAG, nonHDL, apoB, HbA1c as well as pulse wave parameters (DBPao and AiX/75 min) and the association of AOPP with TAG and SBPao were confirmed by multivariate regression analysis. OxLDL showed the largest number of significant correlations, specifically with 
systolic and diastolic aortic pressure and augmentation index. LDL oxidation occurs in patients with DM to form oxidized LDL (OxLDL), which contributes to the pro-inflammatory environment. The dorsal spinal ganglia express the lecithin-like oxLDL receptor (LOX-1). The signaling cascade is activated by the binding of OxLDL to LOX-1, which increases ROS production and contributes to oxidative stress [5]. LOX-1 receptors have also been found in monocytes, which are attracted to the vessel wall, where they transform into macrophages and are able to bind oxLDL and contribute to pathological processes in blood vessels, such as impaired vascular stiffness. Exposure to various pro-inflammatory and proatherogenic stimuli has been shown to increase LOX-1 expression in vivo [30]. In our study, we found the strongest correlation with oxLDL in vascular stiffness parameters (SBP et al., DBP et al., AiX/75 bpm), which may indicate a relationship between microand macrovascular complications of diabetes. Ergo, OxLDL can be considered a risk factor for vascular stiffness progression, as confirmed by a study by Otsuki et al. in a healthy middle-aged and elderly population, where an independent association of serum LOX-1 and PWV was demonstrated [31], as well as a large study by Brinkley et al. with 2295 participants (cohort from the Health, Aging and Body Composition study), where the association between oxLDL and PVW was demonstrated even after adjusting for demographic and traditional risk factors for cardiovascular disease [32]. In the diabetic population, oxLDL has been studied in newly diagnosed patients with type $2 \mathrm{DM}$ and the association between oxLDL and PWV has also been confirmed [33]. The evaluated correlations of oxLDL were demonstrated in our study in a group of patients, where the median LDL was $1.75 \mathrm{mmol} / \mathrm{L}$ in patients with complications and $2.3 \mathrm{mmol} / \mathrm{L}$ in controls, i.e., patients without complications. These numbers correspond to the LDL target values according to the guidelines for the treatment of dyslipidemia (from 2016; the study was completed in 2019), so that subjects can be considered a sufficiently hypolipidemic control.

Apart from a statistically significant correlation of AOPP with central systolic blood pressure (SBP), we did not find any other relationship between the measured oxidative stress parameters (AGE and MDA) and vascular stiffness. Recently, a significant correlation of AOPP with PWV, CRP, HDL-C and HbA1c has been observed in patients with chronic kidney disease [34]. In contrast, another recent study in patients with and without metabolic syndrome did not show an association between MDA levels, vascular stiffness, and components of metabolic syndrome [35]. However, a study in patients with newly diagnosed DM showed a significant correlation between MDA parameters, sRAGE (soluble AGE receptor) and arterial stiffness [36]. Recently, in 2021, Birukov et al. released a study on 3535 participants, when AGEs measured by skin autofluorescence were associated with PWV and AiX, independent of potential cardiometabolic confounders and glycemic status of the participants (patients with type 2 diabetes, prediabetes and normoglycemic) [37]. This confirms the findings of a previous study from 2017, which enrolled patients with DM, prediabetes and normoglycemic subjects $(n=218)$, when plasma AGEs concentration was similarly associated with PWV in all subjects [38]. Other conflicting results were obtained in a large cohort of patients $(n=7735)$, elderly men with and without DM (age between 71 and 92 years), who demonstrated an association between sRAGE and AP and AiX parameters, but no correlation with PVW and central pressures has been demonstrated [39]. The discrepancy in these results can be partly explained by the methodological approaches, the small cohorts of data used in some studies and/or the different patients involved.

Furthermore, the objective of our study was to demonstrate the effect of alphalipoic acid on the levels of oxidative markers. Following short-term infusion therapy $(10 \times 600 \mathrm{mg}$ i.v./5 days), we demonstrated a significant reduction in AOPP, AGE and oxLDL levels, while MDA levels did not change significantly. Studies evaluating the effect of alpha-lipoic acid on oxidative stress reduction provide conflicting results. For example, some studies confirm a reduction in oxidative stress markers (MDA, superoxide dismutase SOD, glutathione peroxidase GPx, prostaglandin PGF2 $\alpha$ and 8-hydroxy-2'-deoxyguanosine) after oral administration of 300-1200 mg/day in patients with type 2 DM [40,41]. Furthermore, ALA can reduce the formation of advanced glycation end products by decreasing of 
circulating glucose concentration and then prevent it from reacting with proteins and subsequently decrease the expression of the AGE receptor in the cell membrane [42]. In contrast, Sharman et al. show no effect of $600 \mathrm{mg}$ /day dose on oxidative marker levels (MDA, SOD, GPx, and catalase) in healthy adults [43]. Similar results were reported by Derosa et al. in 2019, where oral supplementation of $600 \mathrm{mg} /$ day in type $2 \mathrm{DM}$ patients had no effect on oxidative stress (8-isoprostaglandin, SOD, GPx, total antioxidant status TAS, antioxidant gap AOPAP, receptor for advanced glycation end-products RAGE) [44]. In contrast, a study evaluating the effect of intravenous alpha-lipoic acid (600 mg i.v./day for 2 weeks) in obese type 2 DM patients reported a reduction in oxLDL, MDA and 8-isoprostaglandin [45]. Available studies have conflicting results, but it can be concluded that the administration of higher doses and the intravenous form may have a greater effect.

A limitation of this case-control study may be the relatively small size of the cohort. On the other hand, it is one of the few studies evaluating the effect of alpha-lipoic acid on the reduction of oxidative markers in DM patients with neuropathy and evaluating their relationship to vascular stiffness.

\section{Conclusions}

In our study in type $2 \mathrm{DM}$ patients, we demonstrated a correlation between the level of oxidative markers and the parameters of metabolic control in DM patients. Moreover, we showed a correlation of oxidation markers with vascular stiffness.

Furthermore, we demonstrated a significant reduction in oxidative markers (oxLDL, AOPP, AGEs) in patients with type 2 DM after the administration of alpha-lipoic acid used to treat diabetic neuropathy. These oxidative markers not only cause damage to neurons, but also affect the vessel wall, where they contribute to increased vascular stiffness, an independent predictor of CV morbidity and mortality according to the Framingham study [46]. CV disease is known to be the leading cause of death in the DM population.

This is confirmed by our therapeutic and preventive approach to DM patients who must be considered a high-risk group, requiring interventions already in the asymptomatic phase of their lives, with the reduction of risk factors to the lowest possible level, thus preventing serious and potentially fatal complications (myocardial infarction, cerebrovascular accident, ischemic disease of the lower limbs, etc.)

Author Contributions: D.M.: literature search, manuscript writing, methodology, investigation, clinical methods; M.P.: methodology, laboratory methods; D.K., L.C., O.K. and J.Z.: literature search and critical reading; all authors: manuscript revision. All authors have read and agreed to the published version of the manuscript.

Funding: This research was funded by grant number MZ ČR-RVO (FNOl, 00098892).

Institutional Review Board Statement: The study was conducted according to the guidelines of the Declaration of Helsinki, and approved by the Institutional Ethics Committee of University Hospital Olomouc (approval no. 120/18).

Informed Consent Statement: Informed consent was obtained from all subjects involved in the study. Written informed consent has been obtained from the patients to publish this paper.

Data Availability Statement: The data that support the findings of this study are available on request from the corresponding author (D.M.). The data are not publicly available due to protection of personal data of the patients. Informed consent was obtained from all subjects involved in the study. Written informed consent was obtained from the patients to publish this paper.

Conflicts of Interest: The authors declare no conflict of interest. The funders had no role in the design of the study; in the collection, analyses, or interpretation of data; in the writing of the manuscript, or in the decision to publish the results. 


\section{Abbreviations}

\begin{tabular}{|c|c|}
\hline Ao DBP & aortic diastolic pressure \\
\hline AGE & advanced glycation end-products \\
\hline $\mathrm{AiX}$ & augmentation index \\
\hline ALA & alpha-lipoic acid, thioctic acid \\
\hline AOPP & advanced oxidation protein products \\
\hline Ao PBP & aortic pulse pressure \\
\hline Ao SBP & aortic systolic pressure \\
\hline $\mathrm{AP}$ & augmentation pressure \\
\hline ApoA & apolipoprotein $\mathrm{A}$ \\
\hline ApoB & apolipoprotein B \\
\hline BMI & body mass index \\
\hline $\mathrm{BP}$ & blood pressure \\
\hline BPM & beats per minute \\
\hline Chol & cholesterol \\
\hline Chol/HDL & cholesterol and HDL ratio \\
\hline CRP & C-reactive protein \\
\hline DM & diabetes mellitus \\
\hline ECG & electrocarography \\
\hline EMG & electromyography \\
\hline GPx & glutathione peroxidase \\
\hline $\mathrm{HbA}_{1 \mathrm{c}}$ & glycated haemoglobin \\
\hline HDL & high density lipoprotein, \\
\hline LDL & low density lipoprotein \\
\hline LOX-1 & lecithin-like oxLDL receptor \\
\hline MACE & major cardiovascular events \\
\hline MDA & malondialdehyde \\
\hline NADPH & nicotinamid adenin dinucleotide phosphate \\
\hline NOS & nithic oxide synthase \\
\hline DNA & deoxyribonucleic acid \\
\hline nonHDL & $\begin{array}{l}\text { cholesterol contained in potentially atherogenic lipoprotein particles (LDL, IDL, VLDL, } \\
\text { residual chylomicrons) }\end{array}$ \\
\hline $\mathrm{OHA}$ & oral hypoglycemic agents \\
\hline OxLDL & oxidized low density lipoprotein \\
\hline PAI-1 & plasminogen activator inhibitor 1 \\
\hline PWV & pulse wave velocity \\
\hline ROS & reactive oxygen species \\
\hline SOD & superoxide dismutase \\
\hline sRAGE & soluble AGE receptor \\
\hline TAG & triacylglycerols \\
\hline TAS & total antioxidant status \\
\hline
\end{tabular}

\section{References}

1. American Diabetes Association. Introduction: Standards of Medical Care in Diabetes-2020. Diabetes Care 2020, 43 (Suppl. 1), S1-S2. [CrossRef]

2. Brownlee, M. Biochemistry and molecular cell biology of diabetic complications. Nature 2001, 414, 813-820. [CrossRef] [PubMed]

3. Salway, J.G.; Whitehead, L.; Finnegan, J.A.; Karunanayaka, A.; Barnett, D.; Payne, R.B. Effect of myo-inositol on peripheral-nerve function in diabetes. Lancet 1978, 2, 1282-1284. [CrossRef]

4. Ott, M.; Gogvadze, V.; Orrenius, S.; Zhivotovsky, B. Mitochondria, oxidative stress and cell death. Apoptosis 2007, 12, 913-922. [CrossRef] [PubMed]

5. Vincent, A.M.; Hayes, J.M.; McLean, L.L.; Vivekanandan-Giri, A.; Pennathur, S.; Feldman, E.L. Dyslipidemia-induced neuropathy in mice: The role of oxLDL/LOX-1. Diabetes 2009, 58, 2376-2385. [CrossRef] [PubMed]

6. Guo, K.; Elzinga, S.; Eid, S.; Figueroa-Romero, C.; Hinder, L.M.; Pacut, C.; Feldman, E.L.; Hur, J. Genome-wide DNA methylation profiling of human diabetic peripheral neuropathy in subjects with type 2 diabetes mellitus. Epigenetics 2019, 14, 766-779. [CrossRef] [PubMed]

7. Román-Pintos, L.M.; Villegas-Rivera, G.; Rodríguez-Carrizalez, A.D.; Miranda-Díaz, A.G.; Cardona-Muñoz, E.G. Diabetic Polyneuropathy in Type 2 Diabetes Mellitus: Inflammation, Oxidative Stress, and Mitochondrial Function. J. Diabetes Res. 2016, 2016, 3425617. [CrossRef] 
8. Ziegler, D.; Ametov, A.; Barinov, A.; Dyck, P.J.; Gurieva, I.; Low, P.A.; Munzel, U.; Yakhno, N.; Raz, I.; Novosadova, M.; et al. Oral treatment with alpha-lipoic acid improves symptomatic diabetic polyneuropathy: The SYDNEY 2 trial. Diabetes Care 2006, 29, 2365-2370. [CrossRef]

9. Ametov, A.S.; Barinov, A.; Dyck, P.J.; Hermann, R.; Kozlova, N.; Litchy, W.J.; Low, P.A.; Nehrdich, D.; Novosadova, M.; O'Brien, P.C.; et al. The sensory symptoms of diabetic polyneuropathy are improved with alpha-lipoic acid: The SYDNEY trial. Diabetes Care 2003, 26, 770-776; Erratum in Diabetes Care 2003, 26, 2227. [CrossRef] [PubMed]

10. Papanas, N.; Ziegler, D. Efficacy of $\alpha$-lipoic acid in diabetic neuropathy. Expert Opin. Pharmacother. 2014, 15, 2721-2731. [CrossRef]

11. Vallianou, N.; Evangelopoulos, A.; Koutalas, P. Alpha-lipoic Acid and diabetic neuropathy. Rev. Diabet. Stud. 2009, 6, 230-236. [CrossRef]

12. Prenner, S.B.; Chirinos, J.A. Arterial stiffness in diabetes mellitus. Atherosclerosis 2015, 238, 370-379. [CrossRef] [PubMed]

13. Sugiura, T.; Dohi, Y.; Takase, H.; Yamashita, S.; Fujii, S.; Ohte, N. Oxidative Stress is Closely Associated with Increased Arterial Stiffness, Especially in Aged Male Smokers without Previous Cardiovascular Events: A Cross-Sectional Study. J. Atheroscler. Thromb. 2017, 24, 1186-1198. [CrossRef]

14. Kawamoto, R.; Ninomiyax, D.; Kusunoki, T.; Kasai, Y.; Ohtsuka, N.; Kumagi, T. Oxidative stress is associated with increased arterial stiffness in middle-aged and elderly community-dwelling persons. J. Clin. Gerontol. 2016, 7, 136-140. [CrossRef]

15. Witko-Sarsat, V.; Friedlander, M.; Capeillère-Blandin, C.; Nguyen-Khoa, T.; Nguyen, A.T.; Zingraff, J.; Jungers, P.; DescampsLatscha, B. Advanced oxidation protein products as a novel marker of oxidative stress in uremia. Kidney Int. 1996, 49, 1304-1313. [CrossRef]

16. Villa, M.; Parravano, M.; Micheli, A.; Gaddini, L.; Matteucci, A.; Mallozzi, C.; Facchiano, F.; Malchiodi-Albedi, F.; Pricci, F. A quick, simple method for detecting circulating fluorescent advanced glycation end-products: Correlation with in vitro and in vivo non-enzymatic glycation. Metabolism 2017, 71, 64-69. [CrossRef] [PubMed]

17. Laurent, S.; Cockcroft, J.; Van Bortel, L.; Boutouyrie, P.; Giannattasio, C.; Hayoz, D.; Pannier, B.; Vlachopoulos, C.; Wilkinson, I.; Struijker-Boudier, H.; et al. Expert consensus document on arterial stiffness: Methodological issues and clinical applications. Eur. Heart J. 2006, 27, 2588-2605. [CrossRef] [PubMed]

18. Gajdova, J.; Karasek, D.; Goldmannova, D.; Krystynik, O.; Schovanek, J.; Vaverkova, H.; Zadrazil, J. Pulse wave analysis and diabetes mellitus. A systematic review. Biomed. Pap. Med. Fac. Univ. Palacky Olomouc Czech Repub. 2017, 161, 223-233. [CrossRef]

19. Rhee, S.Y.; Kim, Y.S. The Role of Advanced Glycation End Products in Diabetic Vascular Complications. Diabetes Metab. J. 2018, 42, 188-195. [CrossRef]

20. Giacco, F.; Brownlee, M. Oxidative stress and diabetic complications. Circ. Res. 2010, 107, 1058-1070. [CrossRef]

21. Abdul-Ghani, M.A.; DeFronzo, R.A. Oxidative stress in type 2 diabetes mellitus. In Oxidative Stress in Aging; Miwa, S., Beckman, K., Muller, F., Eds.; Humana Press: Totowa, NJ, USA, 2008; pp. 191-211.

22. Spahis, S.; Borys, J.M.; Levy, E. Metabolic Syndrome as a Multifaceted Risk Factor for Oxidative Stress. Antioxid. Redox Signal. 2017, 26, 445-461. [CrossRef]

23. Vona, R.; Gambardella, L.; Cittadini, C.; Straface, E.; Pietraforte, D. Biomarkers of Oxidative Stress in Metabolic Syndrome and Associated Diseases. Oxid. Med. Cell. Longev. 2019, 2019, 8267234. [CrossRef]

24. Alessi, M.C.; Poggi, M.; Juhan-Vague, I. Plasminogen activator inhibitor-1, adipose tissue and insulin resistance. Curr. Opin. Lipidol. 2007, 18, 240-245. [CrossRef]

25. Jung, R.G.; Motazedian, P.; Ramirez, F.D.; Simard, T.; Di Santo, P.; Visintini, S.; Faraz, M.A.; Labinaz, A.; Jung, Y.; Hibbert, B. Association between plasminogen activator inhibitor-1 and cardiovascular events: A systematic review and meta-analysis. Thromb. J. 2018, 16, 12. [CrossRef]

26. Juhan-Vague, I.; Alessi, M.C.; Mavri, A.; Morange, P.E. Plasminogen activator inhibitor-1, inflammation, obesity, insulin resistance and vascular risk. J. Thromb. Haemost. 2003, 1, 1575-1579. [CrossRef]

27. Bilgili, S.; Celebiler, A.C.; Dogan, A.; Karaca, B. Inverse relationship between adiponectin and plasminogen activator inhibitor-1 in metabolic syndrome patients. Endocr. Regul. 2008, 42, 63-68.

28. Edwards, J.L.; Vincent, A.M.; Cheng, H.T.; Feldman, E.L. Diabetic neuropathy: Mechanisms to management. Pharmacol. Ther. 2008, 120, 1-34. [CrossRef]

29. Cardoso, C.R.; Salles, G.F. Aortic Stiffness as a Surrogate Endpoint to Micro- and Macrovascular Complications in Patients with Type 2 Diabetes. Int. J. Mol. Sci. 2016, 17, 2044. [CrossRef] [PubMed]

30. Siti, H.N.; Kamisah, Y.; Kamsiah, J. The role of oxidative stress, antioxidants and vascular inflammation in cardiovascular disease (a review). Vascul. Pharmacol. 2015, 71, 40-56. [CrossRef]

31. Otsuki, T.; Maeda, S.; Mukai, J.; Ohki, M.; Nakanishi, M.; Yoshikawa, T. Association between plasma sLOX-1 concentration and arterial stiffness in middle-aged and older individuals. J. Clin. Biochem. Nutr. 2015, 57, 151-155. [CrossRef]

32. Brinkley, T.E.; Nicklas, B.J.; Kanaya, A.M.; Satterfield, S.; Lakatta, E.G.; Simonsick, E.M.; Sutton-Tyrrell, K.; Kritchevsky, S.B Plasma oxidized low-density lipoprotein levels and arterial stiffness in older adults: The health, aging, and body composition study. Hypertension 2009, 53, 846-852. [CrossRef] [PubMed]

33. Ha, C.Y.; Kim, J.Y.; Paik, J.K.; Kim, O.Y.; Paik, Y.H.; Lee, E.J.; Lee, J.H. The association of specific metabolites of lipid metabolism with markers of oxidative stress, inflammation and arterial stiffness in men with newly diagnosed type 2 diabetes. Clin. Endocrinol. 2012, 76, 674-682. [CrossRef] 
34. Vinereanu, I.V.; Peride, I.; Niculae, A.; Tiron, A.T.; Caragheorgheopol, A.; Manda, D.; Checherita, I.A. The Relationship between Advanced Oxidation Protein Products, Vascular Calcifications and Arterial Stiffness in Predialysis Chronic Kidney Disease Patients. Medicina 2021, 57, 452. [CrossRef] [PubMed]

35. Sri-Amad, R.; Huipao, N.; Prasertsri, P.; Roengrit, T. Aortic Pulse Wave Velocity, Ankle-Brachial Index, and Malondialdehyde in Older Adults with or without Metabolic Syndrome. Pulse 2020, 8, 31-39. [CrossRef]

36. Villegas-Rodríguez, M.E.; Uribarri, J.; Solorio-Meza, S.E.; Fajardo-Araujo, M.E.; Cai, W.; Torres-Graciano, S.; Rangel-Salazar, R.; Wrobel, K.; Garay-Sevilla, M.E. The AGE-RAGE Axis and Its Relationship to Markers of Cardiovascular Disease in Newly Diagnosed Diabetic Patients. PLoS ONE 2016, 11, e0159175. [CrossRef]

37. Birukov, A.; Cuadrat, R.; Polemiti, E.; Eichelmann, F.; Schulze, M.B. Advanced glycation end-products, measured as skin autofluorescence, associate with vascular stiffness in diabetic, pre-diabetic and normoglycemic individuals: A cross-sectional study. Cardiovasc. Diabetol. 2021, 20, 110. [CrossRef] [PubMed]

38. Liu, C.-Y.; Huang, Q.-F.; Cheng, Y.-B.; Guo, Q.-H.; Chen, Q.; Li, Y.; Wang, J.-G. A Comparative Study on Skin and Plasma Advanced Glycation End Products and Their Associations with Arterial Stiffness. Pulse 2017, 4, 208-218. [CrossRef] [PubMed]

39. Wannamethee, S.G.; Welsh, P.; Papacosta, O.; Ellins, E.A.; Halcox, J.P.J.; Whincup, P.H.; Sattar, N. Circulating soluble receptor for advanced glycation end product: Cross-sectional associations with cardiac markers and subclinical vascular disease in older men with and without diabetes. Atherosclerosis 2017, 264, 36-43. [CrossRef] [PubMed]

40. Porasuphatana, S.; Suddee, S.; Nartnampong, A.; Konsil, J.; Harnwong, B.; Santaweesuk, A. Glycemic and oxidative status of patients with type 2 diabetes mellitus following oral administration of alpha-lipoic acid: A randomized double-blinded placebo-controlled study. Asia Pac. J. Clin. Nutr. 2012, 21, 12-21.

41. Derosa, G.; D'Angelo, A.; Romano, D.; Maffioli, P. A Clinical Trial about a Food Supplement Containing $\alpha$-Lipoic Acid on Oxidative Stress Markers in Type 2 Diabetic Patients. Int. J. Mol. Sci. 2016, 17, 1802. [CrossRef] [PubMed]

42. Shay, K.P.; Moreau, R.F.; Smith, E.J.; Smith, A.R.; Hagen, T.M. Alpha-lipoic acid as a dietary supplement: Molecular mechanisms and therapeutic potential. Biochim. Biophys. Acta 2009, 1790, 1149-1160. [CrossRef]

43. Sharman, J.E.; Gunaruwan, P.; Knez, W.L.; Schmitt, M.; Marsh, S.A.; Wilson, G.R.; Cockcroft, J.R.; Coombes, J.S. Alpha-lipoic acid does not acutely affect resistance and conduit artery function or oxidative stress in healthy men. Br. J. Clin. Pharmacol. 2004, 58, 243-248. [CrossRef]

44. Mendoza-Núñez, V.M.; García-Martínez, B.I.; Rosado-Pérez, J.; Santiago-Osorio, E.; Pedraza-Chaverri, J.; Hernández-Abad, V.J. The Effect of $600 \mathrm{mg}$ Alpha-lipoic Acid Supplementation on Oxidative Stress, Inflammation, and RAGE in Older Adults with Type 2 Diabetes Mellitus. Oxid. Med. Cell. Longev. 2019, 2019, 3276958. [CrossRef]

45. Zhang, Y.; Han, P.; Wu, N.; He, B.; Lu, Y.; Li, S.; Liu, Y.; Zhao, S.; Liu, L.; Li, Y. Amelioration of lipid abnormalities by $\alpha$-lipoic acid through antioxidative and anti-inflammatory effects. Obesity 2011, 19, 1647-1653. [CrossRef]

46. Mitchell, G.F.; Hwang, S.J.; Vasan, R.S.; Larson, M.G.; Pencina, M.J.; Hamburg, N.M.; Vita, J.A.; Levy, D.; Benjamin, E.J. Arterial stiffness and cardiovascular events: The Framingham Heart Study. Circulation 2010, 121, 505-511. [CrossRef] 